\title{
Estudo do fluxo de processo para readequação de layout em uma empresa do segmento elétrico
}

\author{
Study of the process flow for layout rehabilitation \\ in an electric segment company
}

\author{
Felipe Giraldeli ${ }^{1}$ \\ Tamires Ferreira ${ }^{2}$ \\ Pedro Gomes ${ }^{3}$ \\ Daiane Chiroli ${ }^{4}$ \\ Fernanda Zola ${ }^{5}$ \\ Franciely Aragão ${ }^{6}$
}

1 Universidade Estadual de Maringá felipegiraldeli@hotmail.com

2 Universidade Estadual de Maringá tsferreira2@uem.br

3 Universidade Estadual de Maringá pfogomes2@uem.br

4 Universidade Tecnológica Federal do Paraná daianechiroli@utfpr.edu.br

5 Universidade Tecnológica Federal do Paraná fzola@utfpr.edu.br

6 Universidade Estadual de Maringá fvaragao2@uem.br

\section{Resumo}

O arranjo físico de uma instalação produtiva, tem o propósito de unir recursos transformadores de forma eficiente, para que as atividades industriais trabalhem de forma a obter um desempenho ótimo ao longo do tempo, neste sentido, um layout mal projetado pode acarretar em problemas na eficiência produtiva. Diante do pressuposto, este estudo tem como objetivo realizar uma proposta de um novo layout para os setores de manufatura de uma empresa do ramo elétrico, para isso, se fez necessário o estudo do fluxo do processo produtivo da empresa, bem como do seu layout atual e fluxo de materiais dentro deste espaço. Com os resultados alcançados, e a proposta do novo layout realizada, notou-se que a nova proposta contribuiu para que os objetivos de redução de movimentação entre materiais e pessoas e eliminação de cruzamento dos fluxos, fossem alcançados, garantindo uma melhor produtividade além de melhorias na organização e segurança.

Palavras-chave: Layout. Arranjo Físico. Fluxo de processo.

\section{Abstract}

The physical arrangement of a production facility has the purpose of efficiently linking transforming resources so that industrial activities work in a way that achieves optimum performance over time. In this sense, poorly designed layout can lead to efficiency problems productive. Given the assumption, this study aims to make a proposal for a new layout for the manufacturing sectors of a company in the electric branch, for that, it was necessary to study the flow of the company's production process, as well as its current layout and flow of materials within this space. With the results achieved, it was possible and the proposal of the new layout realized, it was noticed that the new proposal can contribute to the goals of reduction of movement between materials and people, elimination of crossing of flows, are achieved, ensuring better productivity as well as improvements in organization and security.

Keywords: Layout. Physical arrangement. Process flow. 


\section{Introdução}

Nos últimos anos o estudo do layout produtivo vem sendo difundido no meio empresarial, uma vez que o mesmo pode ter um impacto significativo sobre os custos de produção, prazos e produtividade (SOARES, 2011). Logo, o layout assume cunho estratégico, além de proporcionar economia e incremento da produção, levando em consideração uma boa distribuição dos instrumentos de trabalho, pontos de armazenamento e o fator humano envolvido.

Para Silva e Rentes (2012), pode-se definir o layout do setor produtivo de uma organização como "a localização e a distribuição espacial dos recursos produtivos, como máquinas, equipamentos, pessoas, instalações, no chão de fábrica. Esta distribuição impacta diretamente o desempenho da unidade".

O layout de um sistema produtivo tem por objetivo a locação física adequada dos recursos transformadores. Pode-se afirmar que o arranjo físico exige tempo e comprometimento dos envolvidos, podendo se tornar complexa dependendo das dimensões físicas dos recursos transformadores. Caso o estudo de layout for errôneo, podem-se estabelecer padrões de fluxos longos e conflitantes, estoque de materiais indesejados, filas de clientes ao longo da operação, tempos de processamento maiores que o desejado, e operações inflexíveis (SLACK, et al. 2009).

Além do mais, Borba (et. al., 2014) concluíram que para a definição de um arranjo físico que auxilie na melhoria da disposição dos setores fabris, é necessário o amplo conhecimento de todo o processo envolvido, compreendendo o fluxo de processo, suas inter-relações, e principalmente o espaço físico disponível.

Alguns estudos salientam que a identificação do tipo de layout se faz necessário para que a técnica aplicada a sua melhoria seja eficiente, relata
Mariz \& Picchi (2014) neste sentido os tipos de layout podem ser classificados como layout posicional, por processo, celular, e por produto aborda Slack (2009), o autor comenta que cata tipo de arranjo físico tem suas características e particularidades, salientando que os mesmos ainda podem ser combinados e formar um layout hibrido.

Gerlach (2013), afirma que antes de se aplicar melhorias de layout, deve se conhecer o processo produtivo, para isso deve se utilizar ferramentas que consigam identificar processos que não agregam valor, fluxo desordenados, tempos de produção, entre outros. Para isso, o autor afirma que em sua pesquisa foi utilizado o mapeamento de fluxo de valor, o qual proporcionou um conhecimento amplo do processo estudado.

Estudos evidenciam que um arranjo físico errado pode levar a padrões de fluxo longos e confusos, estoque intermediários, tempos de processamento descompassados, fluxos imprevisíveis entre outros problemas. Sendo assim, a elaboração do layout deve envolver as diversas áreas da empresa, pois o correto dimensionamento dos fatores diretos e indiretos de produção são essenciais para a melhor disposição dos processos produtivos (ROCHA et al., 2011).

Logo, o estudo do layout realizado de forma correta e inteligente, promove ganhos simultâneos para a empresa, pois a reestruturação adequada de uma planta fabril gera impacto positivo no desempenho do processo produtivo (Soares et al. 2011).

Para Oliveira et al. (2017), a melhoria no arranjo físico pode proporcionar o aumento da eficiência das operações, em seu estudo o mesmo mostrou a eficácia do rearranjo de uma estrutura fabril por meio do balanceamento de linha.

Para tanto, o objetivo deste estudo, é realizar uma proposta de adequação de layout para uma empresa do setor elétrico, para isso, foi utilizada como ferramenta a técnica SLP (Systematic Layout Planning - Planejamento Sistemático do Layout). 
Neste sentido, em busca de soluções para o problema de layout mal estruturado, existem algumas técnicas utilizadas na elaboração de projetos de arranjo físico, as quais possuem o propósito de aumentar a fluidez e diminuir desperdícios no processo. O método SPL é, segundo Rocha et al. (2011), uma sistematização de projetos de arranjo físico composto por uma estrutura de quatro fases, na primeira fase, se estabelece o local da empresa onde serão planejadas as instalações. $\mathrm{Na}$ segunda, determina-se a posição relativa entre as várias áreas. Na terceira fase indica-se os locais em que serão instaladas cada máquina/equipamento e as características físicas das áreas. Finalmente, na quarta fase, é planejado cada passo de implantação do novo layout.

Os autores Ojaghi et al. (2015) e Vieira et al. (2014), relatam em seus trabalhos que o método SLP possibilita a determinação de um projeto de layout por meio de etapas estruturadas. Rocha et al. (2011) realizaram um estudo de layout através do SLP e verificaram que o método forneceu alternativas para aproveitar melhor o espaço físico, reduzir movimentações de processo e fluxos contínuos e orientados.

O sistema SLP é uma metodologia de projeto de layout que foi desenvolvida para operações de manufatura, que define e integra os elementos produtivos, relacionando-os com o local e arranjo de departamentos, células ou máquinas em uma planta, sem uma preocupação direta com as peculiaridades das operações de serviços, (RAPOSO et al., 2014). No entanto para Santos, Gohr e Laitano (2012), o método SLP quando aplicado em serviços, apresenta a mesma utilidade que normalmente é observada em instalações industriais, desde que, para isso, o modelo leve em consideração que o fluxo de clientes é predominante em grande parte dos sistemas de operações de serviços.

Já Soares et al. (2011), afirmam que a combinação da simulação de processo a outras técnicas de reestruturação de layout, possibilita maiores benefícios. Já Ottoni (2015), propõe o uso da lógica fuzzy alinhada aos algoritmos Multiple e o Corelap, no uso de identificação de melhorias em layout.

Os autores Neumann e Scalise (2015) apontam que o layout de qualquer empresa, quer seja uma indústria ou prestadora de serviços, é o resultado final de uma análise e proposições de um layout após as decisões relacionadas a produtos, processos e recursos de produção terem sido tomadas. Quando uma alternativa de layout é considerada, vem à tona o problema de um completo planejamento para a produção de um novo bem ou serviço. No entanto, tais problemas envolverão cada vez mais situações de relayout de processos já existentes ou na alteração de alguns arranjos em alguns equipamentos.

Neste sentido, o foco principal deste estudo foi propor um novo layout para uma empresa de produtos elétricos, localizada no norte do Paraná, visando melhorar o seu sistema produtivo e todos os elementos que o compõe.

Como problemática tem-se a má utilização do espaço físico que a empresa dispõe e a falta de organização de fluxo de processo. Para isso, tem-se como hipótese a utilização da técnica SLP pode ajudar a ordenação de fluxo e melhoria de disposição de setores, em uma empresa do ramo elétrico? Ou ainda, a melhoria do layout afeta a produtividade, no quesito que se refere ao aumento de itens produzidos, ou ainda a melhoria de fluxo de processo pode auxiliar na minimização dos tempos de produção?

\section{Metodologia}

O trabalho propõe a realização de uma pesquisa que pode ser classificada como qualitativa, de modo específico, quanto aos objetivos, a pesquisa a ser realizada pode ser considerada de natureza exploratória (D’AMBROSIO (2004), Gil (2008)). 
A coleta de dados deste estudo é composta por 5 etapas de coleta de dados, que serão apresentadas a seguir;

1 Primeiramente se fez necessário coletar informações dos produtos mais vendidos, através de consulta das ordens de fabricação durante o período de um ano, que serviu como base para o layout. Através do setor de PCP (Planejamento e Controle da Produção) foram obtidos dados como informações técnicas, do processo produtivo, informação de fabricação e tempo de fabricação com a ajuda do sistema de gerenciamento empresarial da empresa.

2 Posteriormente foi realizada a coleta das dimensões da edificação, máquinas e equipamentos, foi utilizada a trena de $10 \mathrm{~m}$ e trena a laser de $100 \mathrm{~m}$. Com todos os dados e medições necessárias em mãos, foi elaborado um projeto do arranjo físico atual, representando como estão dispostos os setores dentro deste arranjo físico, para isso foi utilizado o Software AutoCad. Este se fez importante no trabalho, pois se pode visualizar como se encontra disposto os recursos que a empresa necessita.

3 De posse dos dados levantados acima, foi elaborado um fluxograma por meio do Software Microsoft Visio, como ferramenta de representação gráfica, para a melhor compreensão do fluxo de processo da empresa. E utilizado a ferramenta diagrama de relacionamento, onde mostra a importância da relação entre cada setor produtivo.

4 Em sequência como para identificação do fluxo do processo, se construiu o diagrama de relacionamento das atividades, a fim de definir uma relação de proximidade dos setores em que o processo ocorre. Portanto a seguinte frase, cada setor é fornecedor e cliente de outro setor dentro da empresa, se faz verdade.
5 Posteriormente, foi elaborado o diagrama de arranjo de atividade, apresentando graficamente a relação entre cada setor do processo.

Por fim, em porte de todos os dados, como, dimensões do espaço físico da empresa e máquinas, fluxo da produção, e diagrama de relacionamento do processo e diagrama de arranjo de atividades bem definidos, foi elaborado uma proposta de um novo layout produtivo.

\section{Desenvolvimento}

\subsection{Caracterização da empresa}

A empresa do presente estudo, onde no trabalho será definida como empresa $\mathrm{X}$ para preservar a imagem da mesma, está a mais de 50 anos no mercado de produtos elétricos, estando localizado no estado do Paraná.

É uma das maiores fabricantes de produtos elétricos do Brasil, atuando neste mercado desde 1962, a empresa oferece uma vasta linha de produtos para distribuição de energia elétrica.

\subsection{Descrição do processo produtivo}

O conhecimento do processo produtivo é fundamental para a elaboração de um projeto de arranjo físico. A seguir, será descrito o processo produtivo da empresa, objeto de estudo deste trabalho.

O processo começa com a chegada de matéria prima vinda de terceiros para o setor de usinagem, onde é feito o corte, dobra e solda desta matéria prima e incorporado alguns acessórios feitos deste mesmo material, seguindo em linha contínua para o setor de tingimento.

No setor de tingimento o processo continua em linha contínua, primeiramente é feito a limpeza desta peça e posteriormente ela recebe a primeira 
camada de tinta base e passa por uma estufa, após a secagem da primeira camada é realizada a pintura com a cor final da peça, passando novamente por outra estufa, logo em seguida a secagem na segunda estufa, são feitas as marcações com tinta preta das especificações do produto. Por último a peça é deixada em espera para posteriormente fazer a incorporação da outra parte que compõe o produto final.

Simultaneamente ao processo de usinagem é dado início no setor de TB que compõem várias máquinas que realizam a mesma função, a matéria prima deste processo chega e é distribuída para as máquinas, dando origem a peça de $\mathrm{TB}$, posteriormente colocado em espera para ser enviado ao setor de TA.

No setor TA, se agrega a peça $\mathrm{TB}$ com as demais matérias primas do processo dando origem a peça de TA. Finalmente a peça fabricada fica em espera para enviar ao setor de AP.

Quando chega ao setor de AP, a peça de TA que está com a peça de TB incorporada, recebe uma nova matéria prima, onde é feita a junção da peça de TA com esta matéria prima, posteriormente são feitas as conexões, passando pela solda e finalmente colocada em estufas para a secagem, estas etapas são feitas em linha contínua, que dá origem a peça de AP.

O próximo setor é o setor de fechamento, que consiste na incorporação da peça que está em estoque no setor de tingimento com a peça de AP retirada das estufas,

Fonte: Autores. dando origem ao produto final, que posteriormente é enviada para o setor de teste.

No setor de teste, são feitos alguns testes, a fim de identificar se o produto está apto para realizar todas as funções que ele foi projetado. No último setor do processo produtivo, basicamente o produto recebe a sua embalagem e então é feita a sua expedição para o consumidor final.

A figura 1 realizada no Software Microsoft Visio, representa o fluxograma da empresa descrito acima.

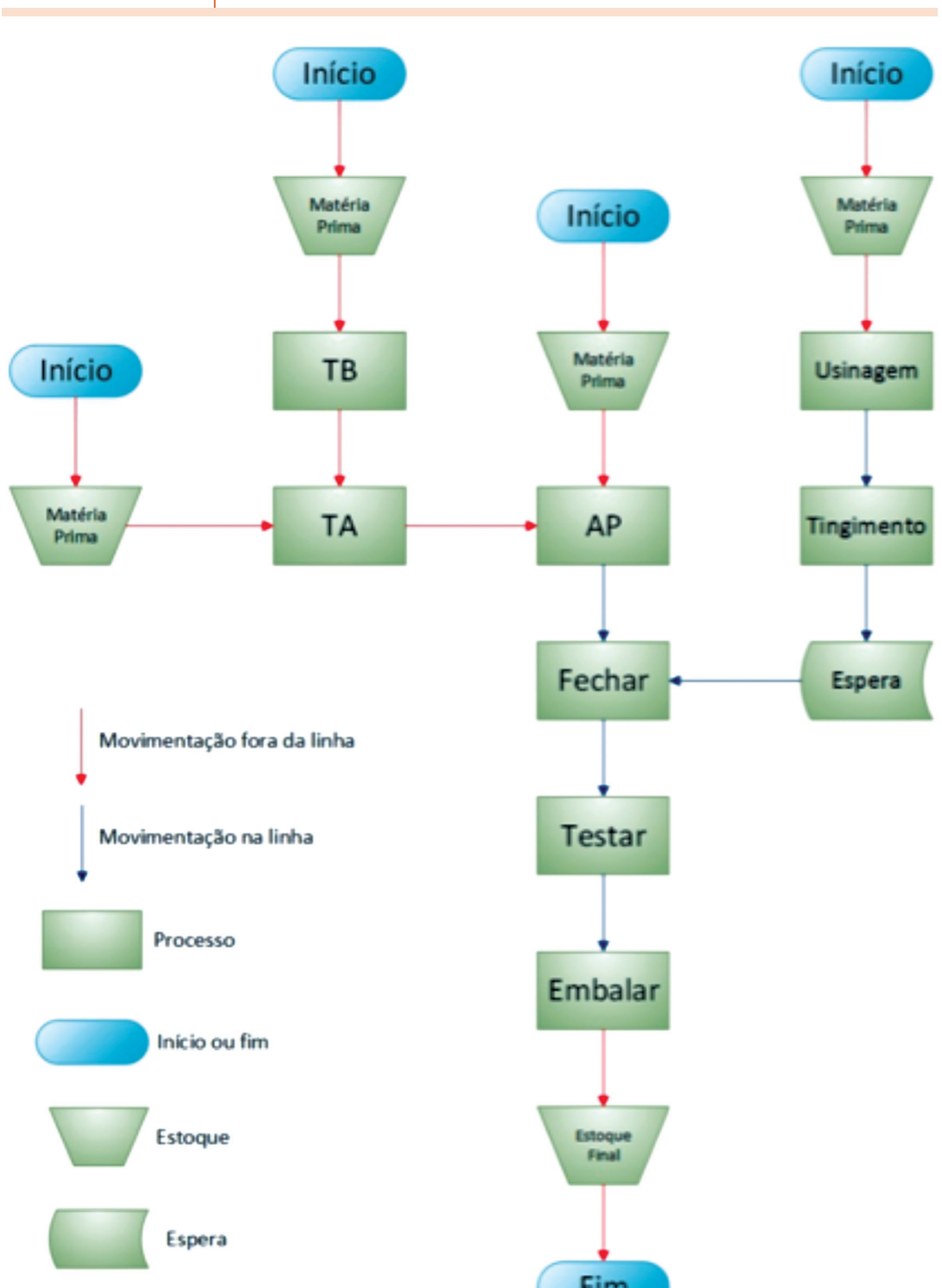

Fim

Figura 1: Fluxo do processo produtivo 


\subsection{Layout atual}

Após ter conhecimento do fluxo do processo, será apresentado o layout atual da empresa de produtos elétricos, mas especificamente a parte final, pois os setores de usinagem e tingimento não serão afetados com a mudança do layout. Para elaborar o arranjo físico foram feitas medições e observações diretas, a fim de ter conhecimento de como os recursos transformadores estão dispostos.

A figura 2 identifica qual fluxo representa cada cor, tanto no layout atual como no proposto.

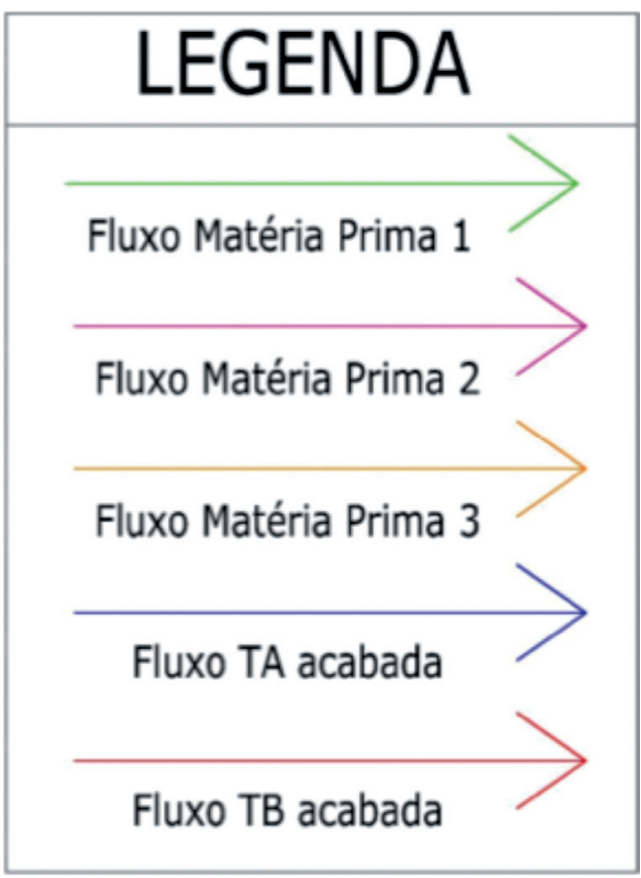

Figura 2: Legenda dos fluxos Fonte: Autores.

Com a utilização do software AutoCad e os dados coletados, podemos representar graficamente como estão dispostos os recursos da empresa no layout atual, como mostra a figura 3 .

A figura 4 mostra o layout aproximado dos setores objetos de estudo deste trabalho, TB, TA e AP.

Um dos pontos mais críticos em relação ao cruzamento de fluxo de materiais está representada abaixo pela figura 5 .

\subsection{Considerações sobre o layout atual}

Com a análise da figura 3, podemos observar que o arranjo físico atual apresenta um fluxo desordenado entre os setores de TB, TA e montagem que são os objetos de estudo deste trabalho. A abertura na parede para a passagem do setor de TB para o restante da fábrica é pequena, pois além de ter o tráfego de peças prontas de TB para o setor de TA, existe o fluxo de matéria prima 1 e o fluxo de pessoas, portanto existe uma grande movimentação em um pequeno espaço.

Algumas máquinas de TB estão localizadas separadas das outras máquinas, o que ocasiona o aumento do fluxo da matéria prima, e o cruzamento do fluxo de peças de TB prontas para o estoque com o de materiais, conforme figura 5 . Outro ponto de melhoria, é que no início do setor de montagem o fluxo de matéria prima 3 cruza com o fluxo de peças de TB para o setor de TA e com o fluxo de peças de TA prontas para o setor de montagem, gerando uma grande movimentação em um pequeno espaço e consequentemente pode ocorrer estresse nos funcionários e acidentes de trabalho.

O espaço onde é armazenada a matéria prima 2, fica distante da entrada da mesma, tendo que atravessar um grande espaço para ser armazenada, além de voltar para abastecer as máquinas do início do setor de TA. Outro destaque, é que os setores fornecedores e clientes uns dos outros, estão com a disposição errada, fazendo com que o caminho que o produto percorre para chegar ao destino é longo e com cruzamentos que podem gerar algum conflito, como perda de tempo acarretando em uma baixa produtividade, como ilustra a figura 4.

Pode se destacar como um ponto falho, o cruzamento de materiais com as demarcações de fluxo de pessoas, podendo gerar acidentes. 


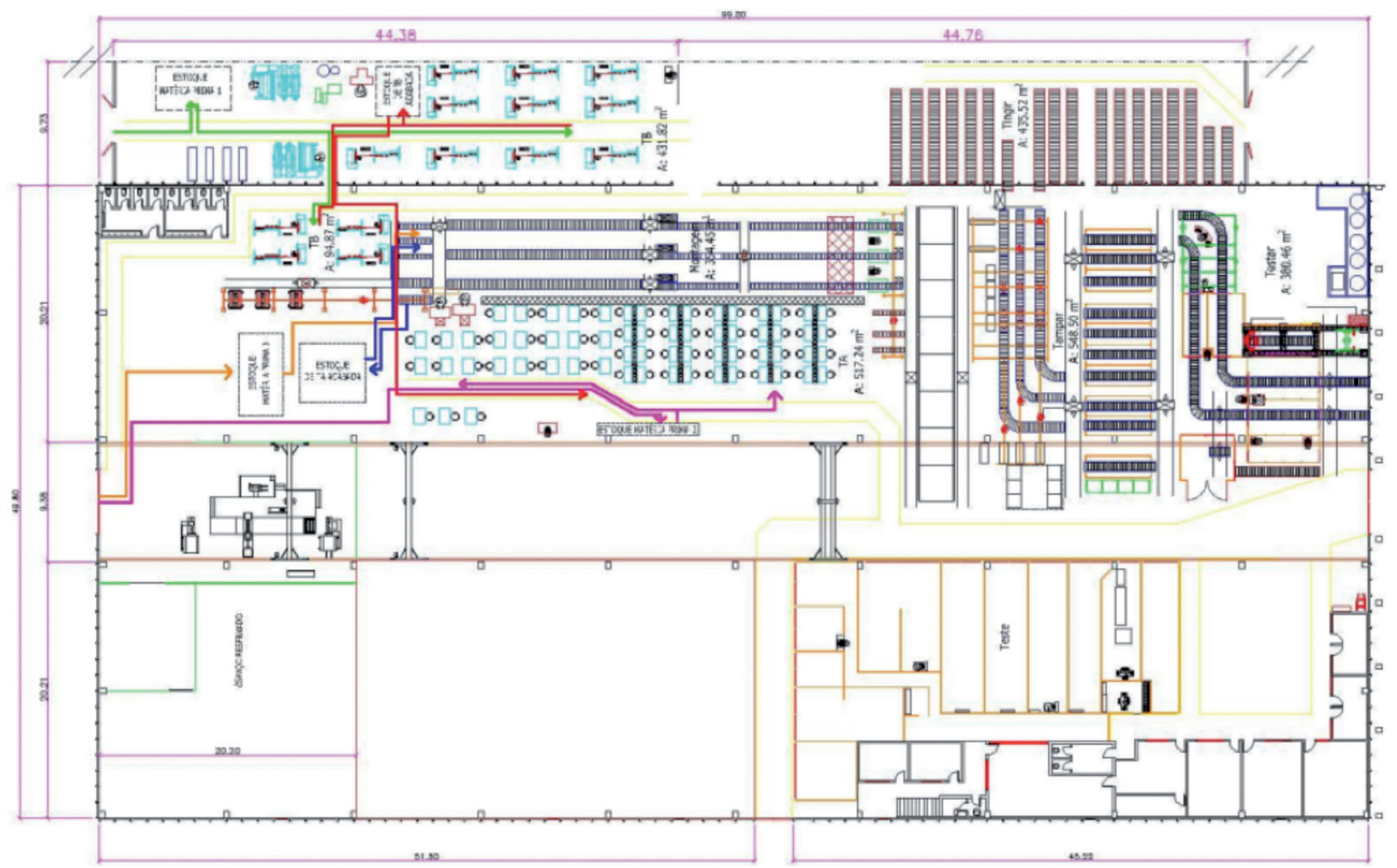

Figura 3: Visão ampla do layout atual

Fonte: Autores.

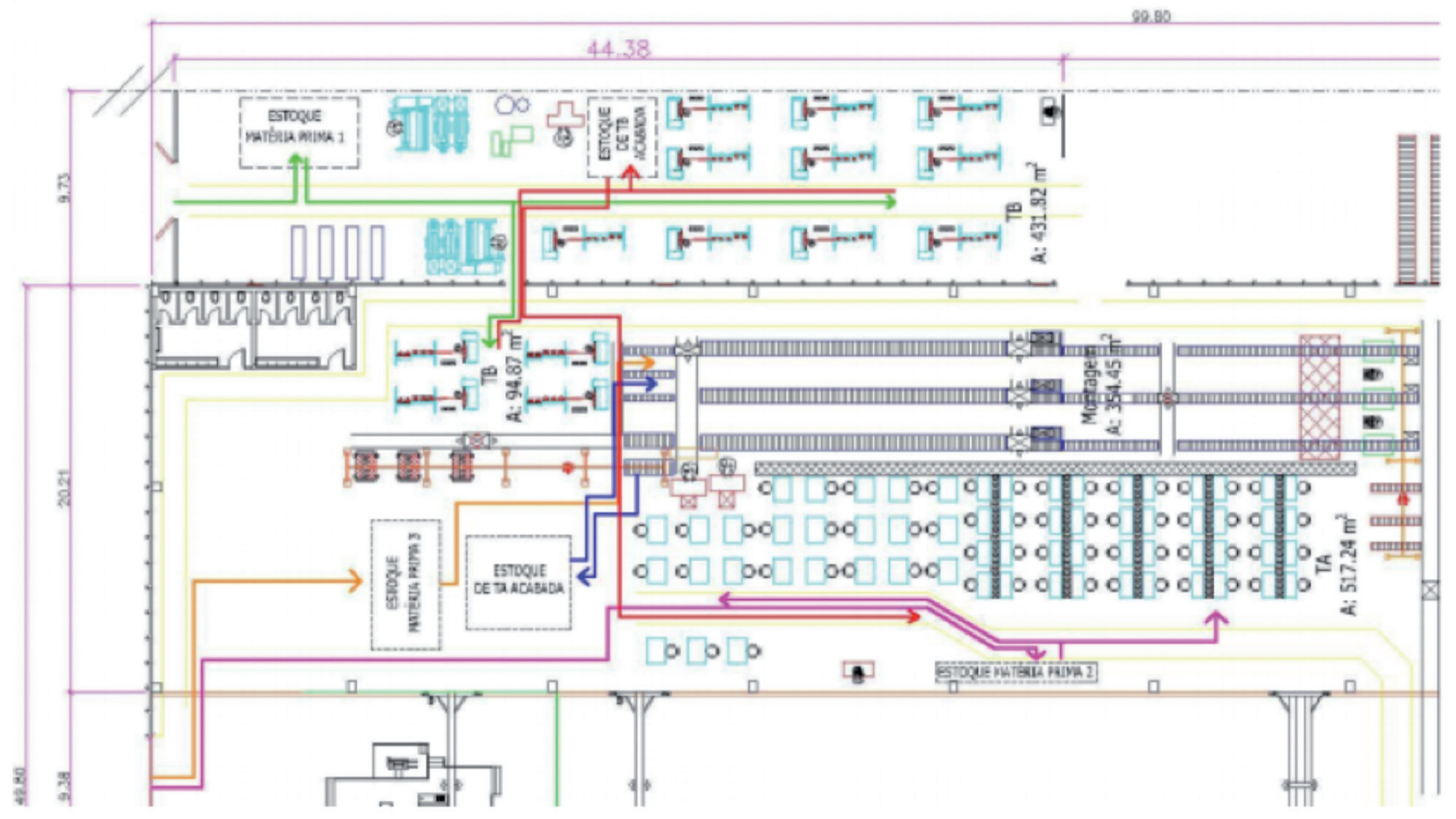

Figura 4: Layout atual dos setores TB, TA e AP

Fonte: Autores. 


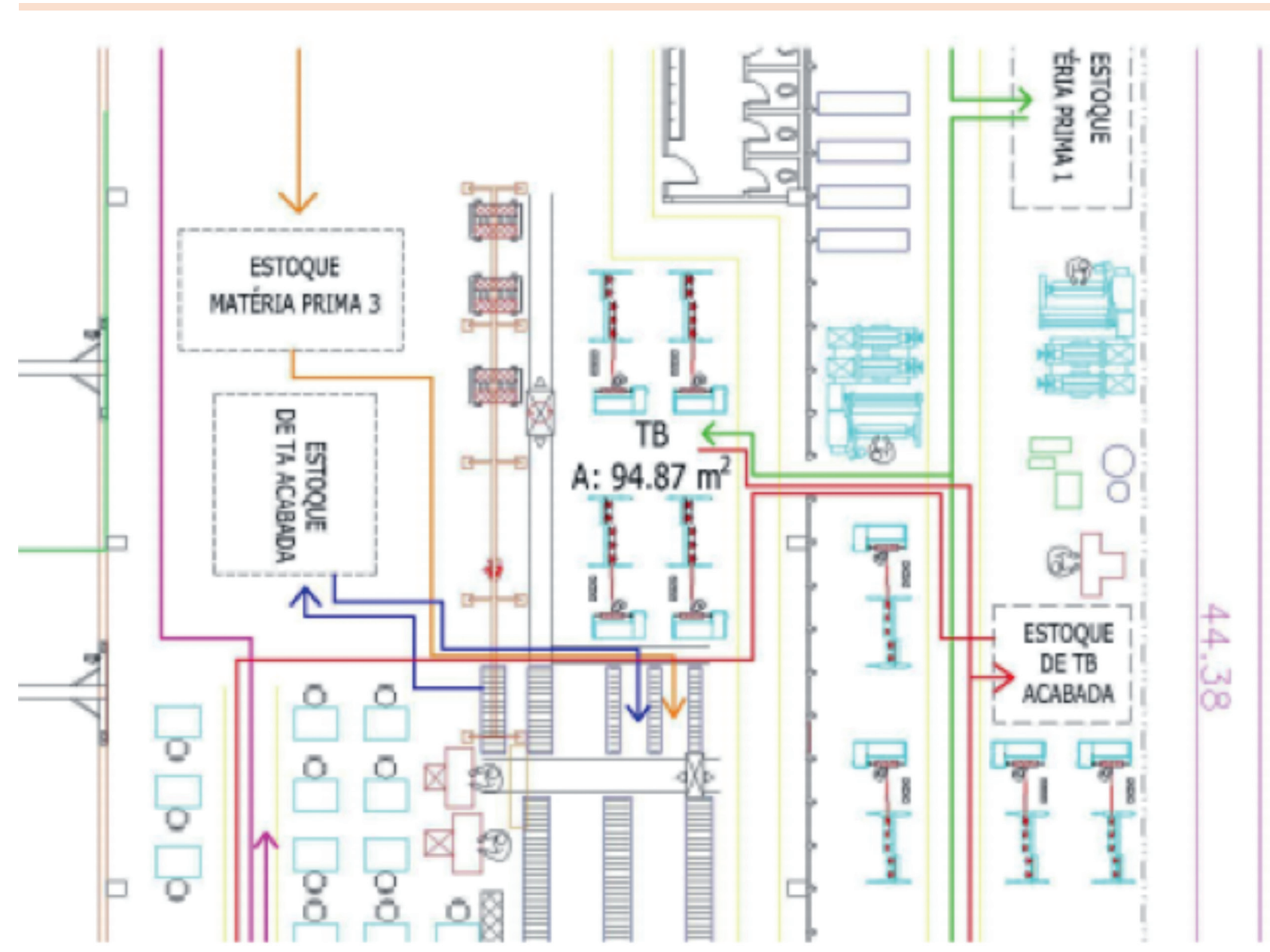

Figura 5: Cruzamento de fluxo de materiais

Fonte: Autores.

O presente layout já se apresenta balanceado, pois não há máquinas e mão de obra ociosas e nem supercarregadas, assim o número de máquinas que se apresentam no layout é o correto para o atendimento da demanda atual da empresa, não se fazendo necessário um novo estudo de balanceamento.

\subsection{Proposta de reestruturação de layout}

$\mathrm{Na}$ elaboração da proposta de reestruturação do arranjo físico, além de considerar o fluxo de operação da empresa e respeitar as dimensões das máquinas, equipamentos e delimitações de estoques, é essencial definir uma relação de pro- ximidade dos setores em que o processo ocorre. Portanto a frase 'cada setor é fornecedor e cliente de outro setor dentro da empresa' se faz verdade.

Para elaborar e definir uma relação de proximidade entre os setores da empresa, utilizou-se o seguinte método: Diagrama de relacionamento. $\mathrm{Na}$ continuidade deste trabalho será apresentada a aplicação prática deste método.

\subsection{Diagrama de relacionamento}

Com os dados obtidos através do fluxograma apresentado na Tabela 1 foi possível realizar o diagrama de relacionamento de atividades, onde foi definido quais operações necessitam de proximidades e quais não necessitam, sendo utilizado 
para isso algumas siglas que definem o grau de proximidade requerido, conforme é apresentado abaixo:

- A - Muito importante;

- E-Importante;

- I - Normal;

- O - Desejável;

- U - Sem importância;

- X - Indesejável.

\begin{tabular}{|c|c|c|c|c|c|c|c|c|c|}
\hline \multicolumn{2}{|c|}{$\begin{array}{l}\text { Diagrama de } \\
\text { Relacionamento }\end{array}$} & $\begin{array}{l}\frac{E}{d} \\
\bar{D} \\
. \frac{c}{\omega}\end{array}$ & 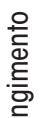 & 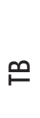 & $\leftleftarrows$ & 妾 & $\begin{array}{l}\text { 흐 } \\
\text { 어 } \\
\text { ㄴ․ }\end{array}$ & $\frac{\text { 홍 }}{\stackrel{\infty}{\infty}}$ & $\begin{array}{l}\text { 흥 } \\
\text { 틀 }\end{array}$ \\
\hline $\mathrm{N}^{\circ}$ & Processo & 1 & 2 & 3 & 4 & 5 & 6 & 7 & 8 \\
\hline 1 & Usinagem & $x$ & A & U & $U$ & U & 0 & 0 & U \\
\hline 2 & Tingimento & & $x$ & U & $U$ & U & A & $U$ & I \\
\hline 3 & TB & & & $X$ & A & E & U & 0 & U \\
\hline 4 & TA & & & & $x$ & $A$ & U & 0 & U \\
\hline 5 & AP & & & & & $x$ & A & 0 & U \\
\hline 6 & Fechar & & & & & & $x$ & A & U \\
\hline 7 & Testar & & & & & & & $X$ & A \\
\hline 8 & Embalar & & & & & & & & $x$ \\
\hline
\end{tabular}

Tabela 1: Diagrama de relacionamento Fonte: Autores.

\subsection{Diagrama de arranjo de atividades}

Após realizar o diagrama de relacionamentos e com os dados obtidos na Figura 6, foi realizado o diagrama de arranjo de atividades, onde é mostrado graficamente a relação existente entre as atividades, utilizando para isso linhas de ligação que representam o grau de proximidade requeridas entre as atividades.

Sendo as atividades com maiores números de ligações, as que devem ficar próximas na elaboração do layout. $\mathrm{O}$ valor das linhas de ligações foi realizado utilizando o grau de proximidade definido na tabela 3, e então para a elaboração deste diagrama são atrelados valores de linhas de liga- ções conforme o grau de proximidade, conforme é mostrado a seguir:

- A - Valor 4, representa 4 linhas de ligação;

- E - Valor 3, representa 3 linhas de ligação;

- I - Valor 2, representa 2 linhas de ligação;

- O - Valor 1, representa 1 linha de ligação;

- U - Valor 0, sem linha de ligação;

- $\mathrm{X}$ - Valor -1, sem linha de ligação.

A seguir na Figura 18, será demonstrado graficamente a relação existente entre as atividades, onde cada número representa uma atividade conforme é apresentado abaixo:

1 Usinagem;

2 Tingimento;

3 TB;

4 TA;

5 AP;

6 Fechar;

7 Testar;

8 Embalar.

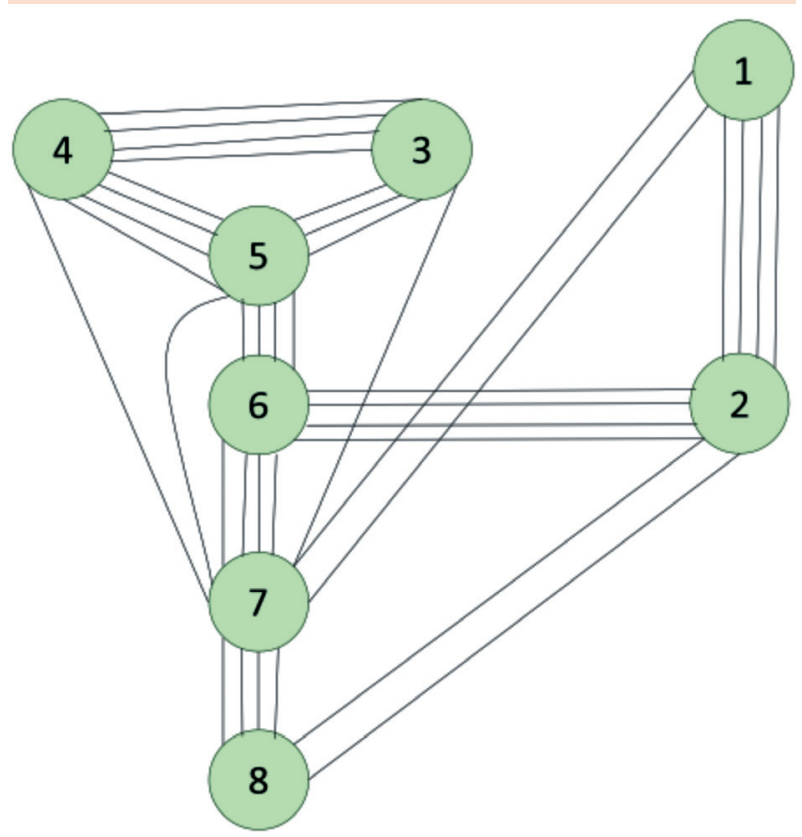

Figura 6 - Diagrama de arranjo de atividades Fonte: Autores. 


\subsection{Proposta de layout}

Após a elaboração do diagrama de relações de espaço apresentado na Figura 6, identificouse quais processos devem permanecer próximos uns dos outros. O próximo passo é direcionar e instalar estes processos, dentro do espaço físico disponível na empresa em estudo, e para isso foi realizado uma planta layout, utilizando o software AutoCad. Para a realização desta planta layout utilizou-se as mesmas medidas do espaço do barracão, que foram coletadas para a realização da planta do layout atual.

O tipo de layout adotado para a elaboração da proposta, levando em consideração o tipo de processo de manufatura e o tipo de processo de serviço que a empresa opera, foi o layout por produto, ou também descrito como layout em linha. Portanto as suas operações seguem um fluxo linear, passando por todas as etapas em sequência, não sendo possível alterar esta ordem. Nos setores TB e TA mesmo não estando em linha, são as máquinas agrupadas que realizam a mesma função.

$\mathrm{Na}$ elaboração da proposta os setores de tingimento, fechar e testar não foram afetados, pois não se faz necessário no momento, tendo em vista que estes setores já estão próximos uns dos outros e os fluxos entre eles estão bem definidos não tendo cruzamentos e o espaço físico destes setores está atendendo as necessidades. Portanto o foco do trabalho são os setores de TB, TA e montagem.

Os espaços de escritório e banheiros como podem ser vistos nas plantas, não sofreram mudanças, pois são áreas de difíceis mudanças. As áreas de teste identificadas se mantiveram no mesmo lugar devido a instalação e os equipamentos utilizados para esta tarefa serem de uma complexidade alta, seria inviável obter uma mudança neste local. Já a área identificada como reservada, faz parte de outro local da empresa e não tem relação alguma com o layout e também por decisão da empresa não poderá deslocar esta área.
O setor de TB, que antes tinha algumas máquinas dentro do mesmo espaço físico que o setor de montagem, mas longe da maioria das máquinas e a chegada do estoque de matéria prima que fica fora deste espaço, geravam uma grande movimentação. A proposta do novo layout apresentou o setor de TB dentro do mesmo espaço físico com todas as máquinas agrupadas e maior espaço entre elas. A chegada da matéria prima deste setor agora é feita pelo lado onde o setor foi instalado.

No novo layout o setor de TA recebeu algumas mudanças, como a disposição das suas máquinas, aumentando o espaço entre elas e melhorando o abastecimento de matéria prima que agora pode ser feito por carrinhos em trilhos. $\mathrm{O}$ estoque de peça de TA pronta não sofreu grandes mudanças, mas foi realocado para não ter o seu fluxo cruzando com outros.

Outra área modificada, foi o setor de montagem, onde as linhas foram espaçadas para melhor convivência dos operadores que trabalham no decorrer delas. Já o estoque de matéria prima do setor de montagem, sofreu a mudança de lugar, ficando mais próximo para abastecer as linhas e sem o cruzamento com outros fluxos.

Os cruzamentos de fluxos que eram constantes no setor de montagem e TA, com a proposta do novo layout não se tem mais cruzamento, gerando mais rapidez no processo, consequentemente aumentando a produtividade e diminuindo custo.

Pode-se ainda falar que com a proposta do layout, entre os setores de TB, TA, montagem, Tampar e Testar não há barreiras físicas, como paredes, por exemplo, facilitando a comunicação entre os setores e rapidez na resolução de problemas que possam vir a ocorrer.

A empresa teve um ganho com esta proposta de um espaço físico que antes era ocupado pelo setor de TB, podendo futuramente expandir a sua produção ou também outros setores da empresa que não estão representados no layout. 
Como foi descrito no tópico do layout atual, a proposta de um novo layout não precisou ser balanceada, pois o número de máquinas representadas é o correto para atendimento da demanda atual da empresa.

A seguir, figura 7, é mostrada a proposta do novo layout já com as modificações para os setores de TB, TA e montagem, podendo ser facilmente percebido o que foi descrito acima.

\subsection{Análise das distâncias entre as atividades}

Foi realizada uma análise das distâncias percorridas em metros entre uma atividade e outra, onde utilizou-se dos projetos do layout atual e da proposta de layout realizados no software AutoCad para medir as distâncias. As distâncias foram medidas utilizando como base o centro de uma atividade produtiva até o centro de outra atividade, como exemplo a medida do centro das máquinas de $\mathrm{TB}$, até o centro do estoque de $\mathrm{TB}$ acabadas e assim por diante.

Estas medições servirão de método comparativo, para definir se a proposta de layout é melhor comparada ao layout atual, em quesitos de redução de deslocamento de materiais dentro da produção.

Na tabela 3, é apresentado as distâncias percorridas durante as atividades no novo layout e no layout proposto.

Após coletado os dados das distâncias percorridas no arranjo físico atual e no proposto, foram analisadas as distâncias totais percorridas nas duas situações somente entre os setores estudados TB, TA e AP, conforme mostra a tabela 4 , a seguir.

Houve uma diferença significativa das distâncias percorridas entre o layout atual e o layout

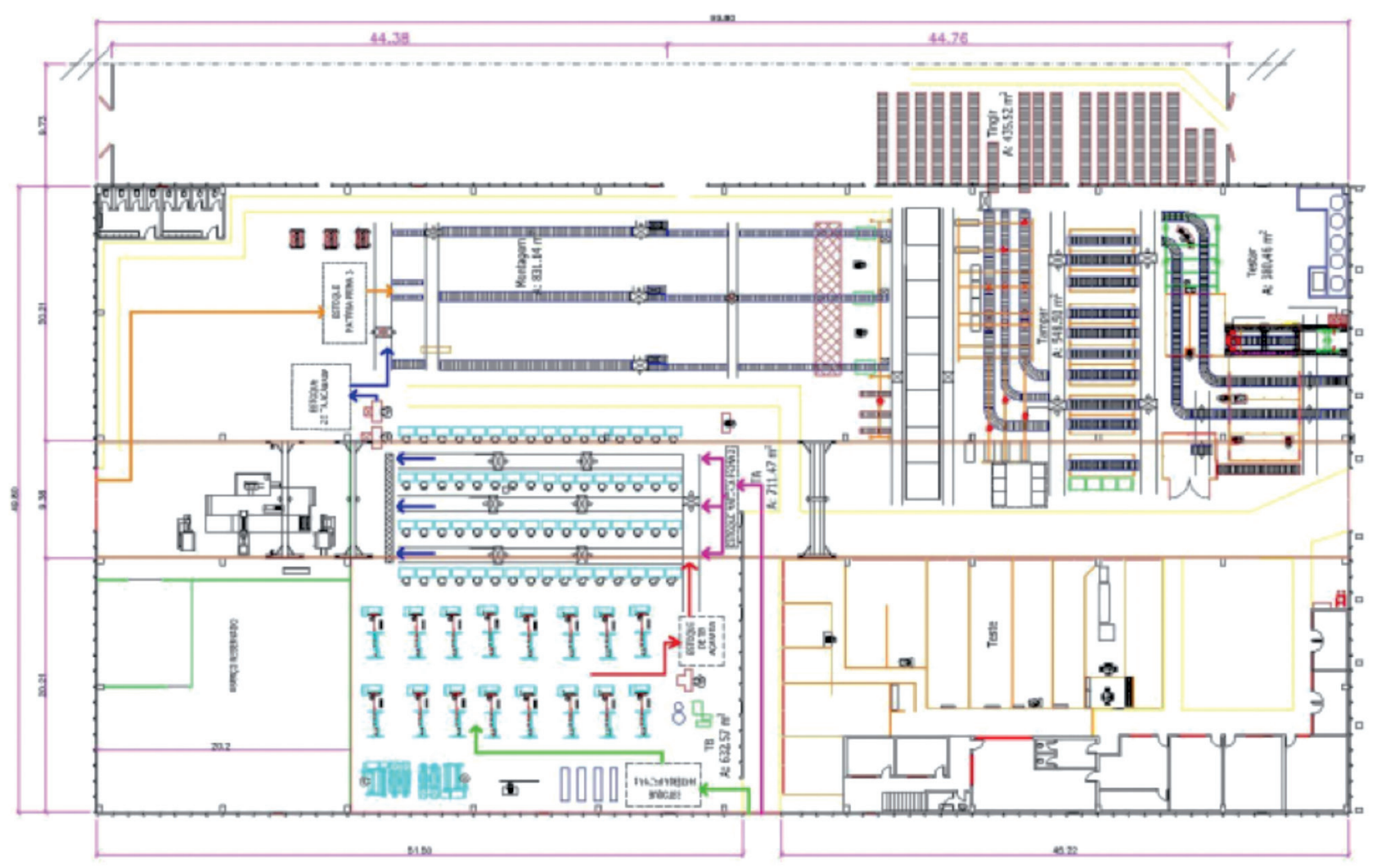

Figura 7: Visão geral do layout proposto.

Fonte: Autores. 


\begin{tabular}{c|c|c}
\hline \multirow{2}{*}{ Ligação entre os processos } & \multicolumn{2}{|c}{$\begin{array}{c}\text { Distância percorrida } \\
\text { em metros }(\mathrm{m})\end{array}$} \\
\cline { 2 - 3 } & $\begin{array}{c}\text { Layout } \\
\text { Atual }\end{array}$ & $\begin{array}{c}\text { Layout } \\
\text { Proposto }\end{array}$ \\
\hline Matéria prima 1 para TB & 39,5 & 26,7 \\
\hline $\begin{array}{c}\text { Peça TB para estoque de TB } \\
\text { acabada }\end{array}$ & 25.3 & 24,6 \\
\hline $\begin{array}{c}\text { Estoque de TB acabada } \\
\text { para TA }\end{array}$ & 54.8 & 17,4 \\
\hline $\begin{array}{c}\text { Matéria prima 2 para TA } \\
\text { Peça TA para estoque de TA } \\
\text { acada }\end{array}$ & 21,3 & 11,4 \\
\hline $\begin{array}{c}\text { Estoque de TA acabada } \\
\text { para AP }\end{array}$ & 6,6 & 1,6 \\
\hline Matéria prima 3 para AP & 28,1 & 12,3 \\
\hline
\end{tabular}

Tabela 3: Análise de distância entre o layout atual e o layout proposto

Fonte: Autores.

\begin{tabular}{c|c}
\hline & $\begin{array}{c}\text { Distância percorrida em } \\
\text { metros }(\mathrm{m})\end{array}$ \\
\hline Layout atual & 178,1 \\
\hline Layout proposto & 100,1
\end{tabular}

Tabela 4: Comparação da distância total percorrida

Fonte: Autores.

proposto. As conclusões relativas a estes dados serão avaliadas no próximo tópico.

Ressalta-se que na aplicação deste estudo, não houve estudos de custos da proposta do novo layout, ficando o mesmo como uma proposta de estudo futuro. Analogamente, ressalta-se que houve uma redução de cerca de $56 \%$ de distância percorrida entre os processos, caso o layout proposto seja implantado, essa minimização de distância, impactara na minimização dos tempos de produção, e por consequências nos custos que o envolvem.

\section{Conclusão}

O estudo de caso elaborado teve como objetivo propor um projeto de layout dos setores de TB, TA e AP de uma empresa do ramo elétrico, visando eliminar características que não agregam valor ao produto e melhorar o fluxo de materiais dentro da empresa.

Após uma comparação do projeto do arranjo físico atual da empresa com o novo projeto proposto, é de fácil observação que as melhorias que a proposta apresenta terão grandes resultados. Primeiramente, com o acesso apropriado para as matérias primas de cada setor, os espaços dos setores delimitados e os equipamentos alocados adequadamente, resultam em um melhor fluxo interno, que é um dos principais processos que não agregam valor ao produto.

O layout proposto apresenta uma solução viável para o fluxo cruzado de matéria prima dos setores e produtos acabados para o próximo setor que dependa desse produto, como por exemplo, a peça de TB acabada para o setor de TA e assim por diante, que é considerado um dos maiores problemas do layout atual e a distância entre os setores gerando movimentações excessivas.

Após análise das distâncias percorridas no layout atual e no layout proposto, podemos concluir que obtivemos uma redução de aproximadamente $43 \%$ na distância total percorrida na comparação entre os dois layouts. Com a aproximação dos processos produtivos de relacionamento forte, o operador terá um ganho significativo em sua eficiência, pois terá que se deslocar uma distância menor e assim diminuirá o tempo de fabricação, o que contribuirá com o aumento da produção e a redução de custos. Desta forma a ordem dos setores segue a ordem de agregação de valor produtivo, evitando que um processo atrapalhe o outro.

Uma proposta de um novo layout envolve diversos fatores que influenciam nos seus aspectos, tornando uma tarefa muito difícil. Dificilmente um projeto não sofrerá alterações durante sua implantação, por isso o mesmo deve ser muito bem estudado e ter um ótimo conhecimento de todo o processo. 
Conclui-se que os objetivos propostos foram alcançados e a proposta de layout apresentada é um projeto viável, pois os problemas que a empresa vem apresentando e foram mencionados no início deste trabalho, como movimentação excessiva de materiais, sequenciamento do fluxo de operações desordenadas, má utilização do espaço físico, foram corrigidos e melhorados.

\section{Referências}

De Borba, M., Luna, M. M. M., \& da Silva, F. A. B. (2016). Proposta de arranjo físico para microempresa baseado no planejamento sistemático de layout (SLP). Revista Produção e Engenharia, 6(1), 519-531.

Borba, M. D. C., \& Araújo, J. D. L. (2004). Pesquisa qualitativa em educação matemática (Vol. 9). Autêntica Editora.

Gil, A. C. (2008). Como elaborar projetos de pesquisa. São Paulo, 5(61), 16-17.

Neumann, C., \& Scalice, R. (2015). Projeto de fábrica e layout (Vol. 1). Elsevier Brasil.

Ojaghi, Y., Khademi, A., Yusof, N. M., Renani, N. G., \& bin Syed Hassan, S. A. H. (2015). Production layout optimization for small and medium scale food industry. Procedia Cirp, 26, 247-251.

Oliveira, I. M. D., da Paz, C. C., da Silva, A. M., \& de Paula Ferreira, W. (2017). Balanceamento de linha e arranjo físico: estudo de caso em uma linha de produção de cabines para máquinas de construção. Exacta, 15(1), 101-110.

Ottoni, G. P. (2015). Aplicação da lógica fuzzy em algoritmos de layout: o caso do restaurante universitário do centro de tecnologia (Doctoral dissertation, Centro de Tecnologia Guilherme Porto Ottoni Projeto de Graduação apresentado ao Curso de Engenharia de Produção da Escola Politécnica, Universidade Federal do Rio de Janeiro).
Silva, A. L. D., \& Rentes, A. F. (2012). Um modelo de projeto de layout para ambientes job shop com alta variedade de peças baseado nos conceitos da produção enxuta. Gestão \& Produção, 19(3), 531-541.

Slack, N., Chambers, S., \& Johnston, R. (2009). Administração da produção (Vol. 747). São Paulo: Atlas.

Soares, J. P. M., de Oliveira Lemos, F., de Araújo, C. L. K., \& Hansen, P. B. (2011). A contribuição da simulação computacional para a análise sistêmica da reestruturação de layout e otimização de recursos na manufatura celular: estudo de caso em uma célula de uma empresa do ramo automotivo. Produto \& Produção, 12(3).

Vieira, N. P. F., Fernandes, F. K. A., Cortez, L. R., de Araújo Nunes, A. M., \& de Araújo, L. E. D. (2014). Aplicação do método SLP para melhoria do arranjo físico: estudo de caso em uma empresa do ramo alimentício. Revista Latino-Americana de Inovação $e$ Engenharia de Produção, 2(3), 74-85.

Mariz, R. N., \& Picchi, F. A. (2014). Aplicação de célula de produção no serviço de execução de fachada: um estudo de caso na construção civil. Revista Produção Online, 14(2), 703-719.

Gerlach, G. (2013). Proposta de melhoria de layout visando a otimização do processo produtivo em uma empresa de pequeno porte. Trabalho Final De Curso para Obtenção do Titulo de Bacharel em Engenharia de Produção. FAHOR, Faculdade Horizontina, Horizontina.

Rocha, F. B. A.; Campos, M. C.; Pacheco, N. O.; Silveira, R. R.; Falani. S. Y. A. (2011) Estudo do layout através do SLP: uma proposta com validação pelo método score para uma fábrica de polpas de frutas. Acessado em 07 de Fevereiro de 2017: http:// www.abepro.org.br/biblioteca/enegep2011_TN_ STO_135_855_18983.pdf

Raposo, J. F. P.; Costa, A. N. M.; Carvalho, K. M. F.; Costa M. G. (2014) Análise e proposta de melhoria de layout de processo numa empresa de fabricação de jogos de mesa. Acessado em 7 de Fevereiro de 2017: http://www.abepro.org.br/biblioteca/enegep2014_TN_ STO_195_104_25098.pdf.

Santos, L. C., Gohr, C. F., \& Laitano, J. C. A. (2012). Planejamento sistemático de layout: adaptação e aplicação em operações de serviços. Revista Gestão Industrial, 8(1).

Recebido em 26 out. 2017 / aprovado em 5 mar. 2018

Para referenciar este texto

Giraldeli, F., Ferreira, T., Gomes, P., Chiroli, D., Zola, F., \& Aragão, F. Estudo do fluxo de processo para readequação de layout em uma empresa do segmento elétrico. Exacta, São Paulo, v. 16, n. 4, p. 79-91. out./ dez. 2018. Disponível em: <https://doi.org/10.5585/ ExactaEP.v16n4.8020> 
H..... . . . 